\title{
Epistemologi dan Ontologi Pendidikan Islam
}

Keywords: Epistemology, Ontology, and Islamic Education

\begin{abstract}
Abstrak
Krisis pendidikan khususnya pendidikan Islam akan sangat berpengaruh terhadap kebijakan atau perilaku sosial hal tersebut mengharuskan kita untuk terus mengembangkan pendidikan khususnya dalam bidang pendidikan Islam. Pendidikan pada umumnya berada dalam lingkup peran, fungsi dan tujuan yang tidak berbeda, Semua bertujuan untuk menegakkan martabat manusia begitu juga halnya dengan tujuan pendidikan Islam. penelitian ini bertujuan untuk mengetahui bagaimana tujuan pendidikan Islam, epistimplogi dan ontologi pendidikan Islam. Penelitian ini merupakan jenis penelitian kepustakaan (library research) yaitu suatu kegiatan penelitian yang dilaksanakan dengan mengumpulkan data dari berbagai jenis literature dari perpustakaan. Jadi, dalam penelitian ini penulis akan mengumpulkan data dari berbagai literature baik dari buku, artikel jurnal dan jenis-jenis karya lain yang berhubungan dengan pokok pembahasan artikel ini. Hasil penelitian menunjukkan bahwa pendidikan Islam bertujuan untuk wujud nilai-nilai Islami dalam pribadi manusia didik yang diupayakan oleh pendidik muslim melalui proses yang menghasilkan sosok anak didik yang berkepribadian muslim, beriman, bertakwa, dan berilmu pengetahuan sehingga sanggup mengembangkan dirinya menjadi menjadi hamba Allah yang taat.
\end{abstract}

Kata Kunci: Epistemologi, Ontologi, dan Pendidikan Islam 


\section{A. Pendahuluan}

Hubungan antara pendidikan dengan masyarakat erat sekali, maka dalam proses perkembangannya saling mempengaruhi. Mesin pendidikan yang kita namakan sekolah dalam proses perkembangannya tidak terlepas dari gerakan mesin sosial. Krisis pendidikan dimanapun selalu sepadan intensitasnya dengan krisis yang melanda masyarakat, pada masa kini manusia sedang berada dalam krisis itu akibat dari pengaruh dari kekuatan ilmu dan teknologi modern yang melaju dengan cepatnya, meninggakan sektor-sektor lainnya (Arifin, 1993). Krisis pendidikan khususnya pendidikan Islam akan berpengaruh terhadap kebijakan atau perilaku sosial hal tersebut mengharuskan kita untuk terus mengembangkan pendidikan khususnya dalam bidang pendidikan Islam.

Pendidikan pada umumnya berada dalam lingkup peran, fungsi dan tujuan yang tidak berbeda. Semua bertujuan untuk menegakkan martabat manusia atau memanusiakan manusia. Dunia pendidikan Islam dengan pendidikan pada umumnya, kadang-kadang memang mempunyai persamaan dan juga memiliki perbedaan ersamaan akan timbul karena sama-sama berangkat dari dua arah pendidikan yakni dari diri manusia yang memang fitrahnya untuk melakukan proses pendidikan, kemudian dari budaya yakni masyarakat yang memang menginginkan usaha warisan nilai, maka semua memerlukan pendidikan.

Pendidikan Islam adalah suatu kegiatan yang sistematis yang melahirkan perubahan progresif pada tingkah laku manusia atau usaha untuk menghilangkan akhlak yang buruk dan menanamkan akhlak yang baik. Pendidikan Islam tentu memiliki peranan penting dalam mempersiapkan generasi menghadapi era yang penuh dengan tantangan, namun tentu tidak semua kita mengetahui apa tujuan dari pendidikan Islam itu sendiri, oleh karena itu dalam makalah ini kita akan mengupas bagaimana pendidikan Islam dan apa saja tujuan dari pendidikan Islam. (Gunawan, 2014). 


\section{B. Metode}

Secara metodologi, penelitian ini merupakan jenis penelitian kepustakaan (library research) yaitu suatu kegiatan penelitian yang dilaksanakan dengan mengumpulkan data dari berbagai jenis literature dari perpustakaan. Jadi, dalam penelitian ini penulis akan mengumpulkan data dari berbagai literature baik dari buku, artikel jurnal dan jenis-jenis karya lain yang berhubungan dengan pokok pembahasan artikel ini.

\section{Hasil dan Pembahasan}

\section{a. Konsep Dasar Pendidikan Islam}

Secara etimologi (bahasa Islami), pendidikan Islam berasal dari dua kata yaitu "pendidikan" dan "Islam". kata pendidikan yang sering kita gunakan, dalam bahasa Arabnya adalah al-Tarbiyah atau Tarbiyah dan sering tertulis serta diucapkan dengan Tarbiyah dapat dijelaskan sebagai berikut: Berasal dari kata dasar "robba- yurabi- tarbiyyatan yang berarti tumbuh dan berkembang (Amrulla, 2007). Sedangkan menurut terminologi pendidikan Islam adalah segala upaya atau proses pendidikan yang dilakukan untuk membimbing tingkah laku manusia, baik individu, maupun sosial untuk mengarahkan potensi, baik potensi dasar (fithrah), maupun ajar yang sesuai fitrahnya melalui proses intelektual dan spiritual berlandaskan nilai Islam untuk mencapai kebahagiaan hidup didunia dan akhirat ( Moh. Haitami Salaim and Syamsul Kurniawan, 2012)

Ilmu pendidikan Islam bisa dipahami sebagai ilmu yang memuat teori-teori kependidikan dalam perspektif Islam dengan berdasarkan pada sumber otentiknya. Teori-teori tersebut harus dapat dipertanggung jawabkan secara akademik dan juga dapat dipraktikkan secara operasional dalam dunia pendidikan. Dengan demikian ilmu pendidikan Islam bukanlah sekedar berisi teori-teori yang ada atau dalil-dalil al-Qur'an dan hadis yang diinterprestasi dan dikaitkan dengan pendidikan, melainkan ilmu yang memuat teori-teori pendidikan yang operasional sesuai dengan dasar kitab suci (Moh. Roqib, 2009) 
Berdasarkan pengerttian di atas para ahli pendidikan Islam mencoba memberikan defisisi pendidikan Islam, inilah beberapa definisi pendidikan Islam menurut para ahli: (Hamruni, Konsep Edutainment Dalam Pendidikan Islam , 2008) Prof. Dr. Omar Mohammad Al-Toumi Al-Syaibany mendefinisikan pendidikan Islam adalah proses mengubah tingkah laku individu pada kehidupan pribdi, masyarakat, dan alam sekitarnya, dengan cara pengajaran sebagai suatu aktivitas asasi dan sebagai profesi di antara profesi-profesi asasi dalam masyarakat. Dr. Muhammad Fadli al-Jamaly mendefinisikan pendidikan Islam adalah upaya mengembangkan, mendorong serta mengajak menusia lebih maju dengan berlandaskan nilai-nilai yang tinggi dan kehidupan yang mulia, sehingga terbentuk pribadi yang lebih sempurna, baik baik yang berkaitan dengan akal, perasaan, maupun perbuatan. Dr. Muhammad S.A. Ibrahimy mendefinisikan pendidikan Islam adalah sebuah sistem pendidikan yang memungkinkan seseorang dapat mengarahkan kehidupannya sesuai dengan ideology Islam, sehingga dengan mudah ia dapat membentuk hidupnya sesuai dengan ajaran Islam.

Landasan atau pondasi dalam pendidikan Islam adalah terdiri dari al-Qur'an dan Sunnah Rasulullah saw yang dapat dikembangkan dengan dengan ijma', qiyas, maslahah mursalah, saddudzdzari'ah, urf, istihsan dan lain sebagainya, karna pendidikan menyangkut ruang lingkup mu'amalah. AlQur'an dan Sunnah adalah dua sumber pokok dalam melakukan ijma' pada semua amal perbuatan dan cara-cara yang islami. Ruang lingkup pendidikan Islam merupakan hal yang berkaitan dengan persoalan-persoalan yang menyeluruh dan mengandung generalisasi bagi semua jenis dan tingkat pendidikan Islam yang baik yang ada di masa sekarang maupun di masa yang akan datan. Dengan kata lain, pendidikan Islam adalah suatu sistem pendidikan yang memungkinkan seseorang dapat mengarahkan kehidupannya sesuai dengan ideology (cita-cita) Islam sehingga ia dengan mudah dapat membentuk dirinya sesuai dengan ajaran Islam. Artinya, ruang lingkup pendidikan Islam telah mengalami perubahan sesuai tuntutan waktu yang berbeda-beda karena sesuai dengan tuntutan zaman dan perkembangan ilmu dan teknologi. 
Dengan demikian, profil manusia yang dihasilkan dari pendidikan Islam adalah manusia yang berkualitas yakni yang beriman dan bertaqwa kepada Allah SWT dan berkemampuan menguasai dan menciptakan ilmu dan teknologi serta sistem budaya hidup berdasarkan nilai-nilai Islami untuk menuju kepada kesejahteraan hidup di dunia dan kebahagiaan di akhirat kelak.

\section{b. Tujuan Pendidikan Islam}

Tujuan dalam pendidikan Islam adalah idealitas (cita-cita) yang mengandung nilai islami yang hendak dicapai dalam proses pendidikan yang berdasarkan ajaran Islam. dengan demikian ini merupakan penggambaran nilai-nilai islami yang hendak diwujudkan dalam pribadi manusia didik pada akhir dari proses tersebut. dengan kata lain, tujuan pendidikan Islam adalah wujud nilai-nilai islami dalam pribadi manusia didik yang diupayakan oleh pendidik muslim melalui proses yang menghasilkan sosok anak didik yang berkepribadian muslim, beriman, bertakwa, dan berilmu pengetahuan sehingga sanggup mengembangkan dirinya menjadi menjadi hamba Allah yang taat. (Hamruni, Konsep Edutainment Dalam Pendidikan Islam, 2008)

Tujuan Pendidikan Islam dalam Al-Qur'an Dan Sunnah Berikut ini adalah sajian tentang berbagai tujuan pendidikan yang bersumber dari alQur'an dan Sunnah Nabi Muhammad SAW. (1) Manusia mengetahui kepada penciptanya dan membangun hubungan di antara keduanya atas dasar ketuhanan Tuhan dan kehambaan makhluk. (2) Mengembangkan perilaku individu (manusia) dan mengubah berbagai orientasi (hidupnya) agar sesuai dengan berbagai tujuan Islam. (3) Melatih individu (manusia) agar menghadapi berbagai kebutuhan hidup yang bersifat material. (4) Meneguhkan umat Islam agar mengikuti ikatan akidah Islamiah dan syariatnya yang adil. (5) Mengarahkan orang-orang muslim untuk memikul (menyebarkan)risalah (ajaran) Islam kepada dunia. (6) Menanamkan iman ke dalam hati dengan persatuan manusia dan persamaan derajat manusia (Gunawan, Pendidikan Islam Kajian Teoritis Dan Pemikiran Tokoh , 2014) 
Sedangkan, menurut para ahli tujuan pendidikan Islam sebagai berikut: Naquib al-Attas menyatakan bahwa tujuan pendidikan Islam adalah manusia yang baik. Kemudian marimba mengatakan bahwa tujuan pendidikan Islam adalah terciptanya orang yang berkepribadian muslim. AlAbrasy menyatakan tujuan (goal) akhir pendidikan Islam itu adalah terbentuknya manusia yang berakhlak mulia (akhla al-karimah). Munir Musyi mengatakan bahwa tujuan akhir pendidikan Islam adalah manusia yang sempurna (al-Insan al Kamil). Majid Irsan al-Kailany menyatakan bahwa tujuan umum pendidikan Islam tergambar menjadi dua hal: (1) bahwasanya tujuan itu dimulai dari individu, kemudian berakhir bagi masyarakat manusia secara umum. (2) bahwasanya tujuan pendidikan itu dimulai dari dunia, kemudian berakhir dengan akhirat, dengan berbagai teknik (metode pendidikan) yang disempurnakan dan saling keterkaitan.

Ahmad Fuad al-Ahwani menyatakan bahwa pendidikan Islam adalah perpaduan yang menyatu antara pendidikan jiwa, membersihkan ruh, mencerdaskan akal, dan menguatkan jasmani. Di sini, yang menjadi fokus dari pendidikan Islam yang dikemukakan oleh Ahmad Fuad al-Ahwani adalah soal keterpaduan. Dari tujuan pendidikan Islam di atas, menurut Moh. Haitami dalam bukunya studi ilmu pendidikan Islam membagi tujuan pendidikan menjadi tiga bagian sebagai berikut: (1) Pendidikan jasmani (alTarbiyah al-jismiyah) Merupakan usaha untuk menumbuhkan, menguatkan, dan memelihara jasmani dengan baik (normal). Dengan demikian, jasmani mampu melaksanakan berbagai kegiatan dan beban tanggung jawab yang dihadapinya dalam kehidupan individu dan sosial. Ada dua sarana untuk membantu keberhasilan pendidikan jasmani, yaitu (a) sarana pendidikan jasmani yang bersifat aktif, meliputi makanan sehat, udara segar, gerak badan atau olahraga dan (b) sarana pendidikan jasmani yang bersifat pasif, seperti kondidi ruangan kelas sehat dan kondusif, jumlah peserta kelas tidak terlalu banyak dan sebagainya. (2) Pendidikan akal (al-Tarbiyah al-Aqliyah) adalah peningkatan pemikiran akal dan latihan secara teratur untuk berfikir benar. Pendidikan intelektual akan mampu memperbaiki pemikiran tentang ragam pengaruh dzn realitas secara tepat dadn benar. Hal ini akan 
menghasilkan keputusan atas segala sesuatu yang dipikirkn menjadi tepat dan benar. Beberapa cara untuk mencapai keberhasilan pendidikan intelektual, yaitu (a) melatih perasaan peserta didik untuk meningkatkan kecermatannya, (b) melatih peserta didik untuk mengamati sesuatu yang bermanfaat bagi kehidupan dunia dan akhirat, (c) melatih daya intuisi sebagai sarana penting bagi daya cipta dan (d) membiasakan anak berfikir teratur (sistematis) dan menanamkan kecintaan berfikir sistematis. (3) Pendidikan akhlak (al-Tarbiayah al-Khuluqiyah) Pendidikan akhlak bertujuan untuk membina kualitas manusia prima dengan cici-ciri antara lain, (a) beriman dan bertaqwa kepada Allah sebagai satu-satunya tuhan, (b) berakal sehat atau mempunya kemampuan akademik, yaitu kemampuan mengembangkan kecerdasannyadengan mencintai ilmu terutama yang sesuai dengan bakatnya, (c) mempunyai kematangan pribadi, berbudi luhur, jujur, amanah,beranih, qanaah, sabar/tangguh, syukur, bertanggung jawab, cinta tanah air, mempertebal semangat kebangsaan dan rasa kesetia kawanan sosial, dan percaya diri, (d) mempunyai keterampilan belajar, bekerja, bermal saleh, disiplin, bekerja keras, mandiri, penuh perilaku yang inovatif dan kreatif, sehat jasmani dan rohani.

Dengan hakikatnya demikian itu dapat, pendidikan Ilsam menuntut sebuah rumusan tujuan yang tentu juga berbeda dengan tujuan pendidikan pada umumnya. Oleh karena basisnya adalah tauhid, tujuan pendidikan Islam pun dengan sendirinya harus mengacu atau tidak dapat dipisahkan dari tujuan hidup manusia yang menjadi objek pendidikan itu sendiri yang sudah disuratkan oleh Allah dalam wahyu-Nya (Sutrisno and Nuhyidin Albarobis, 2012)

Maka dapat disimpulan bahwa tujuan pendidikan Islam sama dengan tujuan dari kehidupan manusia itu sendiri, yaitu untuk mengapdi kepada Allah, menjadi khalifah Allah dibumi, mencari ridha Allah, dan meraih kehidupan di dunia maupun akhirat. 


\section{c. Konsep Dasar Epistimologi, Ontologi Pendidikan Islam}

\section{Epistimologi Pendidikan Islam}

Epistimologi secara etimologi, kata epistimologi berasal dari bahasa Yunani: episteme dan logos. Episteme berarti pengetahuan, sedangkan logos bererti ilmu, teori, uraian atau alasan. Jadi, epistimologi berarti sebuah teori atau ilmu tentang pengetahuan (Armai and Arief, 2002). Epistimologi adalah salah satu komponen filsafat yang membahas tentang bagaimana cara mendapatkan pengetahuan (Hamdani, 1998). Berbicara tentang epistimologi pendidikan Islam tentu akan timbul pertanyaan bagaimana cara mengembangkan ilmu pendidikan? Cara mengembangkan teori pendidikan Islam sangat tergantung kepada karakteristik materinya, apakah materi itu berada dalam pengalaman yang empiris, rasional, hermeneutis. Jika karakteristiknya adalah empiris maka metode yang digunakan adalah obesevasi, eksperimen. Jika karakteristik adalah rasional maka metode yang digunakan adalah deduktif. Jika karakteristik materinya hermeneutis, maka metode yang digunakan adalah verstehen, yakni untuk menangkap makna lebih dalam, sehingg diperoleh kesimpulan kasus, atau metode yang reflektif, yakni metode analisis yang proses mondar-mandir antara yang empiric dengan yang abstrak.

Cara pengembangan ilmu pendidikan Islam bisa menggunakan metode penelitian ilmiah, metode penelitian filosofis, dan menggunakan metode penelitian sufistik. Dalam hal ini maka epistimologi pendidikan Islam adalah sebagai berikut: (1) Berlandaskan pada al-Qur'an dan hadis yang di rancang dengan cara mempertimbangkan konsep ilmu pengetahuan, islamisasi pengetahuan dan karakter ilmu dalam perspektif Islam yang bersandar pada kekuatan keagamaan yang memiliki hubungan harmonis antara akal dan wahyu. (2) Mengutamakan epistimologi Islam yang berbasis kepada tauhid dan pengalaman empiric, dimana dari realitas empiric ini kemudian diamati, di kaji, dan diteliti. (3) Orientasi dan penekanan pada ma'rifah, pengetahuan toritik (Hidayat, 2016). 


\section{Ontologi Pendidikan Islam}

Ontologi berasal berasal dari bahasa Yunani: ontos dan logos. Ontos berarti sesuatu yang berwujud, sedangkan logos berarti ilmu, teori, uraian atau alasan. Secara istilah ontologi berarti hakikat yang dikaji dan hakekat realitas yang ada tentang kebenaran. Ontologi adalah ilmu yang membahas tentang ruang lingkup penelaahan sebuah keilmuan hanya pada lingkup daerah yang berada dalam jangkauan pengalaman manusia secara empiric dalam proses penemuan/ penyusunan pernyataan yang bersifat benar secara ilmiah (Khojir, 2011).

Berdasarkarkan hal tersebut diatas, maka jika pendidikan Islam ingin dikembangkan sebagai sebuah disiplin, maka harus mempunyai wilayah kajian khusus yang membedakan dirinya dari ilmu-ilmu lainnya. Memang bukanlah hal yang mudah dalah menentukan batas-batas kajian pendidikan Islam, karena wilayah pendidikan Islam sangat luas, seluas ajaran agama Islam itu sendiri. Hasan Langgulung berpendapat tema pendidikan Islam bisa mencakup hampir segala macam ilmu pengetahuan yang dimiliki manusia dan mencakup segala aktifitas manusia yang bersangkutan dengan budayanya dan peradabannya, tetapi bisa sempit karena mencakup satu disiplin ilimu yang merupakan ilmu pendidikan sebagai cabang engetahuan yang termasuk kedalam bidang kemanusiaan.

\section{Kesimpulan}

Pendidikan Islam adalah segala upaya atau proses pendidikan yang dilakukan untuk membimbing tingkah laku manusia, baik individu, maupun sosial untuk mengarahkan potensi, baik potensi dasar (fithrah), maupun ajar yang sesuai fitrahnya melalui proses intelektual dan spiritual berlandaskan nilai Islam untuk mencapai kebahagiaan hidup didunia dan akhirat. Tujuan pendidikan sebagai berikut: manusia mengetahui kepada penciptanya dan membangun hubungan di antara keduanya atas dasar ketuhanan Tuhan dan kehambaan makhluk, Mengembangkan perilaku individu (manusia) dan mengubah berbagai orientasi (hidupnya) agar sesuai dengan berbagai tujuan Islam, Melatih individu (manusia) agar menghadapi berbagai kebutuhan 
hidup yang bersifat material, Meneguhkan umat Islam agar mengikuti ikatan akidah Islamiah dan syariatnya yang adil, Mengarahkan orang-orang muslim untuk memikul (menyebarkan)risalah (ajaran) Islam kepada dunia, Menanamkan iman ke dalam hati dengan persatuan manusia dan persamaan derajat manusia.

\section{DAFTAR PUSTAKA}

Amrulla, Djumransjah and Abdul Malik Karim. (2007). Pendidikan Islam Menggali Tradisi Meneguhkan Eksistensi. Malang: UIN-Malang Press.

Arifin, H. (1993). Kapita Selekta pendidikana islam dan umum. Jakarta: Bumi Aksara .

Armai and Arief. (2002). Pengantar Ilmu Dan Metodologi Pendidikan Islam . Jakarta: Ciputat Pers.

Gunawan, H. (2014). Pendidikan Islam Kajian Teoritis Dan Pemikiran Tokoh. Bandung: Remaja Rosdakarya.

Gunawan, H. (2014). Pendidikan Islam Kajian Teoritis Dan Pemikiran Tokoh . Bandung: Remaja Rosdakarya.

Hamdani, I. (1998). Filsafat Pendidikan Islam. Bandung: Pustaka Setia.

Hamruni. (2008). Konsep Edutainment Dalam Pendidikan Islam. Yogyakarta: Bidang Akademik UIN Sunan Kali Jaga.

Hamruni. (2008). Konsep Edutainment Dalam Pendidikan Islam . Yogyakarta: Bidang Akademik UIN Sunan Kali Jaga.

Hidayat, R. (2016). Pendidikan Islam Sebagai Ilmu: Tinjauan Ontologi, Epistimologi Dan Aksiologi. Sabilarrasyad, -.

Khojir, K. (2011). Membangun Paradigma Ilmu Pendidikan Islam: Kajian Ontologi, Epistemologi Dan Aksiologi. Dinamika Ilmu 11, 1.

Moh. Haitami Salaim and Syamsul Kurniawan. (2012). Studi Ilmu Pendidikan Islam. Yogyakarta: Ar-Ruzzmedia.

Moh. Roqib, I. P. (2009). Ilmu Pendidikan Islam Pengembangan Pendidikan Integratif Di Sekolah, Keluarga, Dan Masyarakat. Yogyakarta: LKIS.

Sutrisno and Nuhyidin Albarobis. (2012). Pendidikan Islam Berbasis Problem Sosial. Yogyakarta: Ar-Ruzzmedia. 